\title{
GPPS-TC-2019-0030
}

\section{UNSTEADINESS OF TIP LEAKAGE FLOW IN THE DETACHED-EDDY SIMULATION ON A TRANSONIC COMPRESSOR ROTOR}

\author{
Xiangyu Su \\ Key Laboratory for Thermal Science and \\ Power Engineering of Ministry of Education, \\ Department of Energy and Power Engineering, \\ Tsinghua University \\ su-xy17@mails.tsinghua.edu.cn \\ Beijing, China
}

\author{
Xiaodong Ren \\ Key Laboratory for Thermal Science and \\ Power Engineering of Ministry of Education, \\ Department of Energy and Power Engineering, \\ Tsinghua University \\ rxd@mail.tsinghua.edu.cn \\ Beijing, China
}

\author{
Xuesong Li \\ Key Laboratory for Thermal Science and \\ Power Engineering of Ministry of Education, \\ Department of Energy and Power Engineering, \\ Tsinghua University \\ xs-li@mail.tsinghua.edu.cn \\ Beijing, China
}

\author{
Chunwei Gu \\ Key Laboratory for Thermal Science and \\ Power Engineering of Ministry of Education, \\ Department of Energy and Power Engineering, \\ Tsinghua University \\ gcw@mail.tsinghua.edu.cn \\ Beijing, China
}

\begin{abstract}
Focused on the structure and the unsteady characteristics of tip leakage flow, a numerical investigation of a transonic compressor rotor using detached-eddy simulation (DES) method is carried out. Details of the leakage vortex are better captured with DES method than RANS at different working conditions. At near stall point, it is clearly observed that interaction between tip leakage vortex and the bow shock leads to a vortex breakdown, which directly leads to the unsteadiness at the top region and also causes a blockage, which may further induce a spike-type stall inception.
\end{abstract}

\section{INTRODUCTION}

Tip leakage flow plays an important role in compressor rotors, which is closely related to loss (Denton, 1993) and stall (Vo, 2001) characteristics. As for low-speed compressors, flow structures as well as unsteadiness of tip leakage flow have been widely studied and certain achievements were obtained through numerical efforts and experiments. As the flow coefficient decreases, the interface between the tip leakage flow and the incoming flow moves upstream (Hoying et al., 1998), the trajectory of which will be aligned with the leading edge when the rotor finally encounters a spike-type stall (Vo et al., 2008). Vo came up with a criterion for spike-initiated numerical stall that leading-edge spillage and trailing-edge backflow are both essential, which was proved in low-speed compressor experiments (Deppe et al., 2008). Leading-edge spillage is later found to be an accompanying phenomenon, whose fundamental cause is the tornado-like vortex, resulted from the interaction between tip leakage vortex and leading-edge separation (Yamada et al., 2013). Moreover, attentions were also paid to flow structures and unsteady phenomena, for instance, the bubble-type breakdown of leakage vortex (Furukawa et al., 1998).

With the increase of turbine requirements, the shaft speed of compressors is also increasing to achieve higher stage loading. Conclusions for tip leakage flow in low-speed compressors are not entirely suitable for transonic ones, due to greater pressure gradient and the existence of shock. The interaction between leakage vortex and the shock results in increasing complexity and less stability in the top flow field. Strong self-induced unsteadiness (Zhang et al., 2008; Biela et al., 2008; Du et al., 2013) was found in tip leakage flow with a characteristic frequency near 60\% BPF (blade passing frequency). In addition, leakage vortex breakdown is revealed in transonic compressors, but in another form (Hofmann and Ballman, 2003; Yamada et al., 2004).

Despite the efforts made by scholars in turbomachinary community, the mechanism of tip leakage flow as well as its self-induced unsteadiness are still not fully understood, especially in transonic compressors. Previous investigations have shown that unsteadiness of tip leakage flow is closely related to the interaction between shock and leakage vortex, 
but failed to reveal this interacting process. On the other hand, traditional turbulence models have native defects in the prediction of tip leakage flow (Iim et al., 2013). As a result, DES (detached-eddy simulation) method is thought to be an alternative in capturing separated flow with bearable cost (Spalart et al., 1997). Up to now, many scholars (Yamada et al., 2013; Riéra et al., 2014; Yamada et al., 2017; Lin et al., 2018) have applied DES method to turbomachinery field and achieved satisfactory results.

In this paper, we carried out DES investigations of a transonic compressor rotor, in order to achieve the following results:

a) Detailed flow structure of tip leakage flow and its interacting process with the shock.

b) Unsteady characteristics of tip leakage flow and its fundamental cause.

We would like to conduct a multistage full-annulus DES simulation indeed, but finally turned to a single-row calculation due to the limits of computing resources.

\section{METHODOLOGY}

The compressor used in present study is an in-house 1.5stage transonic axial compressor, with 22 rotor blades and a tip clearance of $0.82 \%$ chord length. Its schematic structure and design parameters are shown in Figure 1 and Table 1 respectively. The computational domain is the rotor part (indicated by red dashed line in Figure 1), with inlet and outlet boundaries extended for one axial chord and two axial chord respectively.

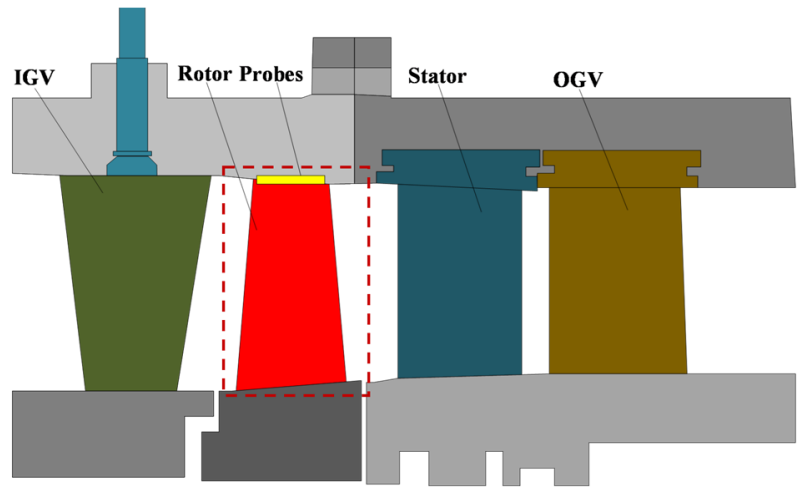

Figure 1 Schematic Structure of the 1.5-Stage Compressor

Table 1 Design Parameters of the Compressor

\begin{tabular}{ccc}
\hline Parameter & Value & Unit \\
\hline Rotating speed & 24840 & $\mathrm{rpm}$ \\
Mass flow & 12 & $\mathrm{~kg} / \mathrm{s}$ \\
Total pressure ratio & 1.3 & - \\
Tip Mach number & 1.25 & - \\
Tip clearance & $0.82 \%$ & chord length. \\
\hline
\end{tabular}

As shown in Figure 2, a relatively coarse grid with zonal refinement is adopted in order to meet the DES requirements. The final mesh is an unstructured hybrid grid containing hexahedron and tetrahedron, with a total element number of
12.3 million, 10 nodes applied in boundary layers to ensure $y^{+}<1$ and 27 nodes applied in the tip clearance region with $\Delta x^{+}, \Delta y^{+}, \Delta z^{+}<20$.

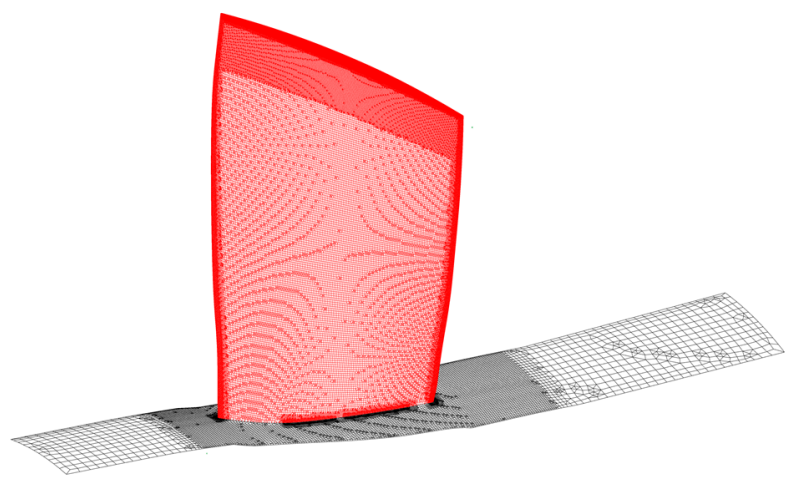

Figure 2 Overview of the DES Computational Grid

A commercial solver package, FLUENT, was used in the present work, which is a three-dimensional, time-accurate code with implicit second-order scheme. For RANS method, the steady Reynolds-averaged Navier-Stokes equations are solved, with turbulence modelled by Spalart-Allmaras oneequation model (Spalart and Allmaras, 1994). For DES method, the DES97 model (Spalart et al., 1997) is used with a default DES coefficient $C_{D E S}$ of 0.65 .

We conduct DES calculations at three working conditions, as shown in Table 2. The physical time of each time step is 1e-6 s, which is small enough to include at least 110 time steps in one blade passing period. Total mass flow and static pressure were monitored during the calculation to ensure a good convergence. Pressure monitors are located on the tip region of the rotor, with eight points on the casing and one on the blade tip, as shown in Figure 3. As for boundary conditions, adiabatic nonslip-wall conditions were adopted for all solid walls. Radial distributions of total pressure, total temperature, and flow angles were given at the inlet using UDF (user-defined function) files. Static pressure distribution was specified at the outlet.

To validate DES results, steady RANS calculations were carried out at corresponding working conditions, based on the same mesh and the same calculation settings with DES calculations except for the flow model.

\section{Table 2 Calculation Settings}

\begin{tabular}{cc}
\hline Parameter & Setting \\
\hline Computational & One R1 passage \\
domain & Near choke point, peak efficiency \\
Working condition & point, near stall point \\
Solver & FLUENT \\
Model & DES97 \\
Time step & $1 \mathrm{e}-6(\mathrm{~s})$ \\
Inner iteration & 15 \\
\hline
\end{tabular}




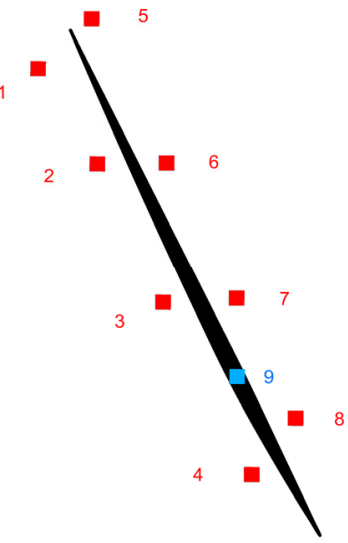

Figure 3 Monitor Points in DES Calculation (red: on casing, blue: on blade tip)

\section{RESULTS AND DISCUSSION}

\section{Validation of DES Calculation}

DES results are compared with corresponding RANS results to ensure a reasonable prediction of the overall flow field. The performance comparison between DES timeaveraged results and RANS results is shown in Figure 4. The maximum deviation of mass flow and total pressure ratio is $0.25 \%$ and $0.94 \%$, respectively. Figure 5 and Figure 6 shows relative flow angle distributions and Figure 7 shows the comparison of relative Mach contour at $99.3 \%$ span (slightly below the blade tip) at near stall point.

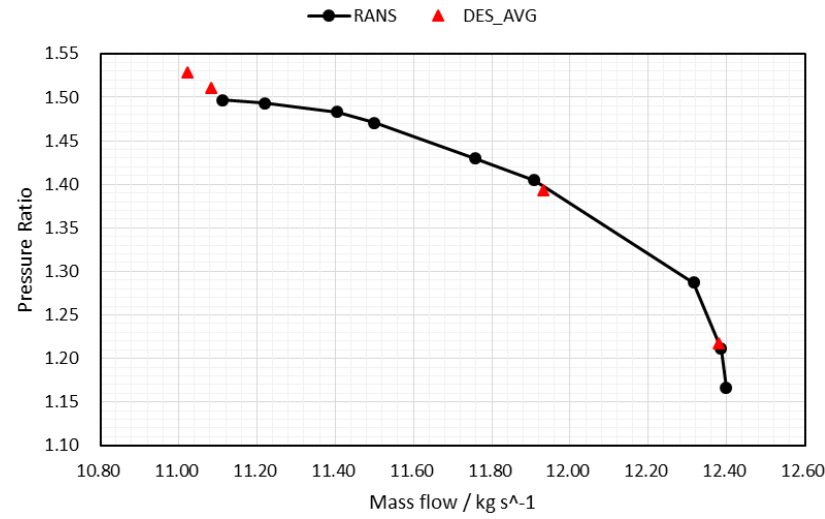

Figure 4 Overall Performance of R1 in DES Calculation Compared With RANS Calculation

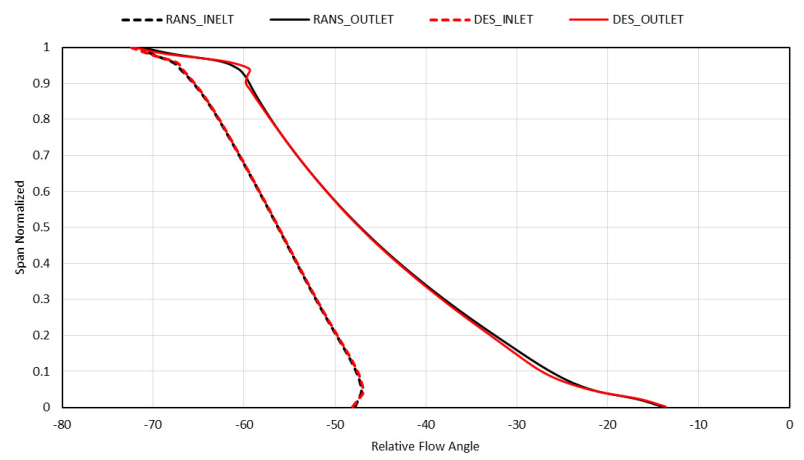

Figure 5 Relative Flow Angle Distribution at Peak Efficiency Point

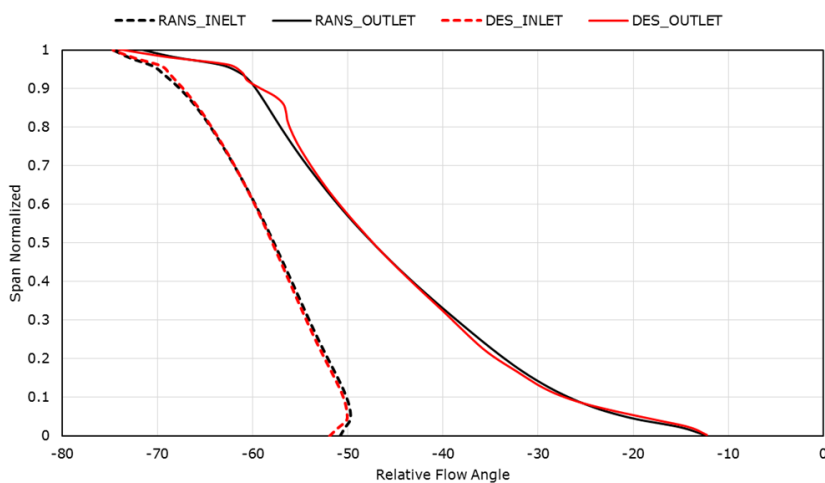

Figure 6 Relative Flow Angle Distribution at Near Stall Point

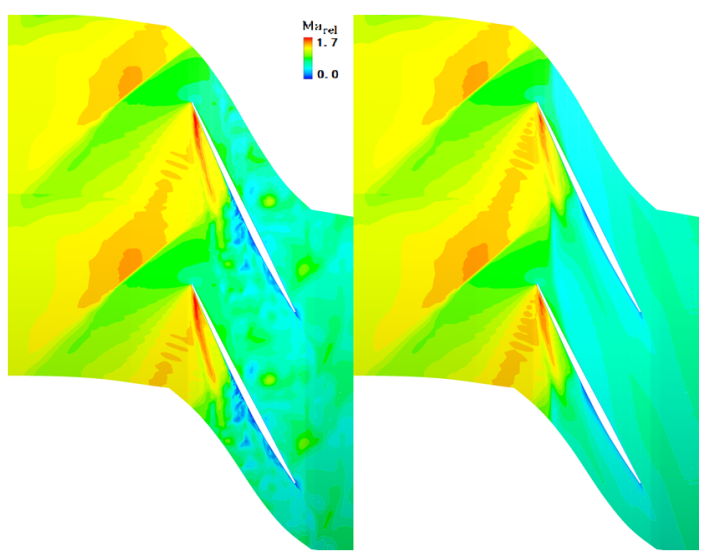

Figure 7 Relative Mach Contour at $99.3 \%$ Span at Near Stall Point (left: DES, right: RANS)

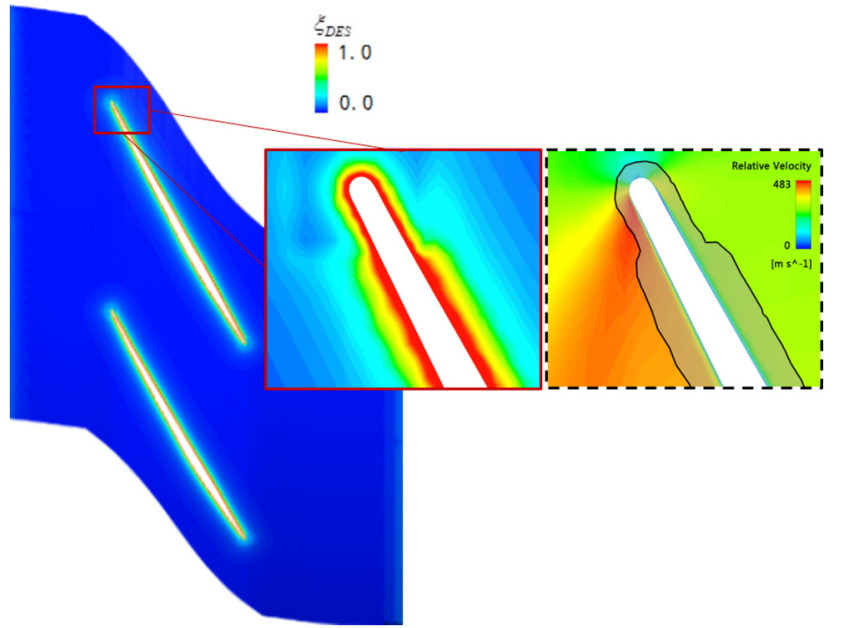

Figure 8 LES and RANS Regions in DES Results at $90 \%$ Span

Moreover, the correct switch of LES and RANS is critical in DES calculations and needs to be checked in present study. A criterion to distinguish LES region from RANS region is as follows:

$$
\xi_{D E S}=\frac{\tilde{d}}{d}=\min \left(1, C_{D E S} \frac{\Delta}{d}\right) \in(0,1]
$$

Where $\xi_{D E S}=0$ indicates LES method is switched on and $\xi_{D E S}=1$ for RANS. Figure 8 shows LES and RANS regions 
in DES calculations, with LES switched on in the mainstream and RANS used inside the boundary layer as expected.

In general, both the overall performance and parameter distributions of the DES results were consistent with RANS results, to some degree. In addition, Mach number distributions in these two results near the top region have no conflicts, indicating tip leakage flow was correctly captured in DES calculation. Along with the reasonable LES/RANS region distribution, it is proved that DES results are relatively reliable in present simulation and can be used for following analysis of the tip leakage flow.

\section{Unsteadiness at Near Stall Point}

The tip leakage flow in high-speed compressors has selfinduced unsteadiness features (Du et al., 2010; Du et al., 2013). In present calculation, by monitoring nine static pressure points, it is found that the fluctuations at near stall point is much stronger than peak efficiency point and near chock point. Therefore, the following part will mainly focus on the unsteadiness at near stall condition.

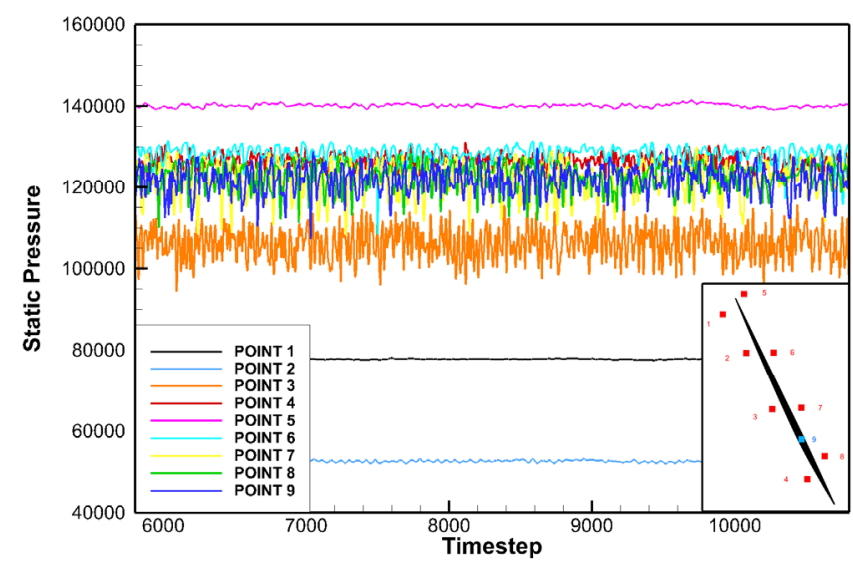

\section{Figure 9 Static Pressure History at Near Stall Point in DES Calculation}

Figure 9 shows the static pressure convergence history of different monitoring points. Point 1 , point 2 and point 5 experienced weaker pressure fluctuation than the rest. It is worth noting that point 1 and point 2 are exactly in the initial trajectory of the leakage vortex and in front of the shock near suction side, while point 5 is at the leading edge and after the bow shock. For transonic rotors, it is typical that the tip leakage vortex starts from the leading edge of tip blade, traveling towards the adjacent pressure side and downstream. It passes through and interacts with the bow shock, then imprints on the adjacent pressure side, and finally develops downstream along the blade surface. In other words, these three points mentioned above are far away from the interaction region of leakage vortex and the shock, indicating that neither the tip leakage vortex nor the shock alone is the root cause of the unsteady flow field. In addition, points 6 to 9, which experienced strong fluctuations in static pressure, are located along the trajectory of tip leakage flow as well. However, what makes difference is that these points are all located after the shock wave. From this aspect, it is exactly the interaction between tip leakage vortex and the shock that leads to the unsteadiness of the tip region. The detailed reasons will be explained in next section.

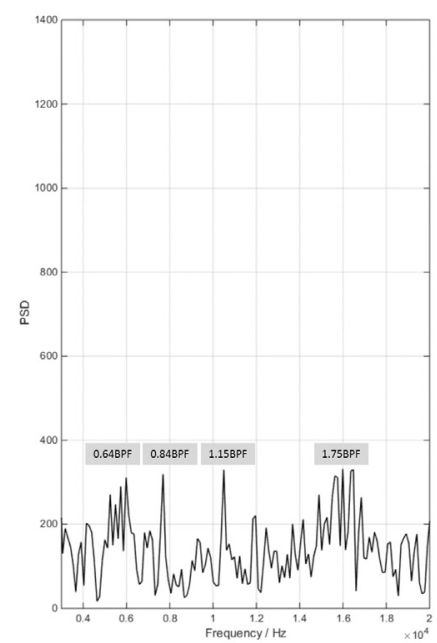

a) Point 3

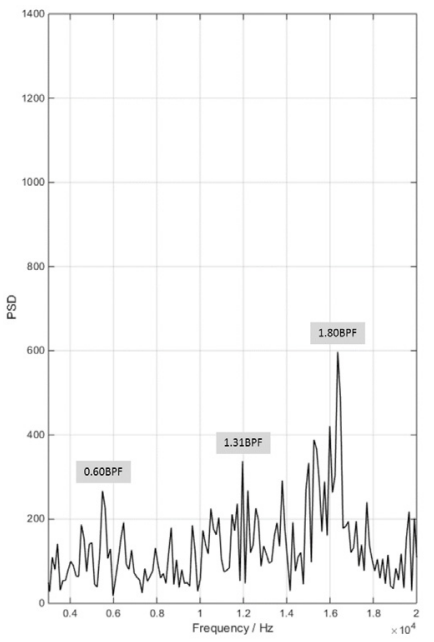

b) Point 6

\section{Figure 10 Spectrum of Certain Monitor Points at Near Stall Point}

Figure 10 shows the spectrum of some representative monitor points at near stall point, which is the result of the fast Fourier transform of the time series data. The frequency characteristics of each point are not exactly the same. Wide though the frequency bands are, they do share some similarities, that is, peak values appeared near two specific frequencies - 0.64 $\mathrm{BPF}$ and 1.80 BPF. It is worth noting that the former is close to the characteristic frequency of tip leakage flow in typical transonic compressors, for instance, 0.6 BPF (Yamada et al., 2004) for NASA Rotor 37 and 0.57 BPF (Biela et al., 2008; Du et al., 2013) for Darmstadt Rotor 1. Other monitoring points with large fluctuation, such as point 8 and point 9 , have similar results as well.

The unsteadiness near the tip region inevitably affected the overall performance and is the critical reason for the fluctuation in overall parameters at near stall point, as shown in Figure 11 and Figure 12. Obvious unsteady feature exists above $80 \%$ span with a fluctuation range of about 10 degrees for the outlet flow angle and 0.1 (about $6.5 \%$ of the timeaveraged total pressure ratio) for the total pressure ratio, while the unsteadiness is weak in the middle and root span, indicating that tip leakage flow is an essential factor causing instability at near stall point. Nevertheless, there is no obvious fluctuation of the static pressure rise coefficient among the whole blade height range, which means the unsteadiness of the top flow field is mainly caused by the fluctuation of kinetic energy and can be a proof for the wakelike nature of the tip leakage vortex when passing through the shock (Puterbaugh and Brendel, 1997). 


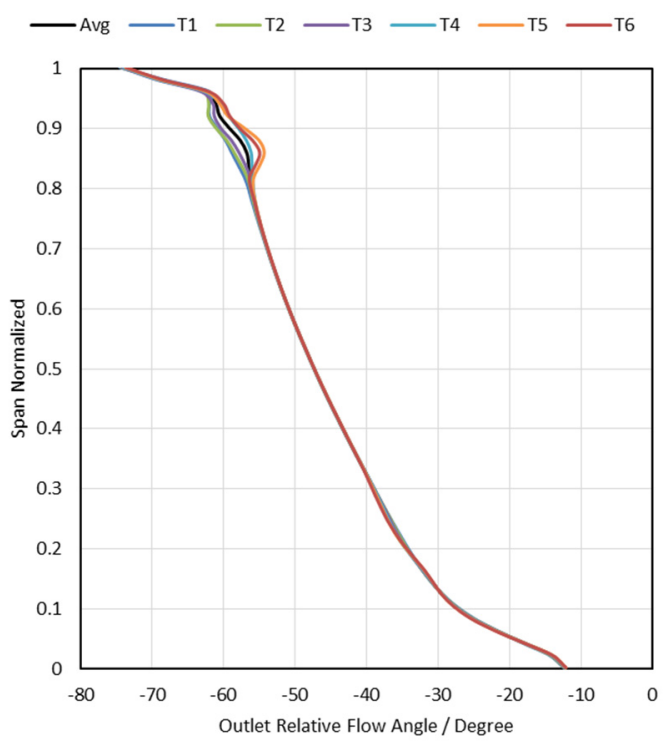

Figure 11 Outlet Flow Angle Distributions at Near Stall Point

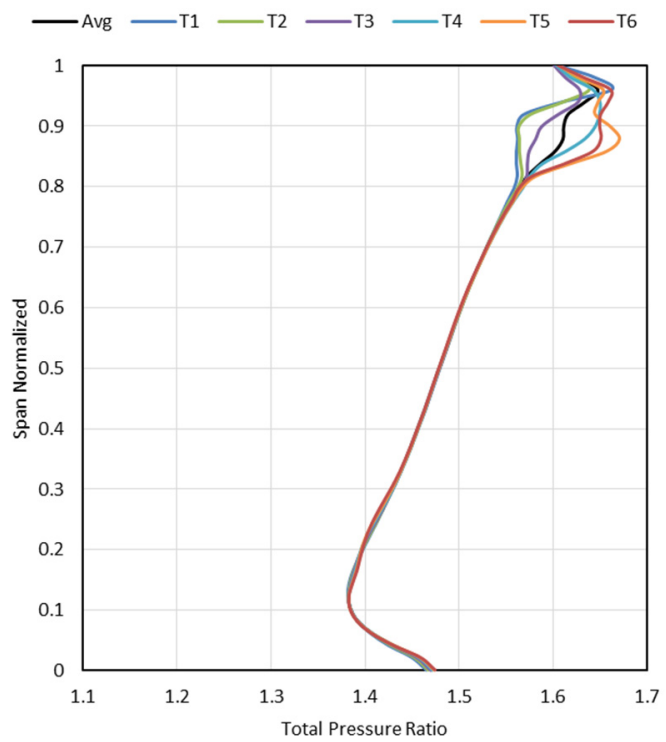

\section{Figure 12 Total Pressure Ratio Distributions at Near Stall Point}

Figure 13 is the top view of R1 shroud with blade profile imprinted. We chose a certain axial location (red line) and obtained its circumferential distribution of static pressure in one period, as shown in Figure 14, taking circumferential angle as the abscissa. There are two low pressure regions, one is at about -1 degrees (indicated by the black arrow) and the other is from -4.5 to -7 degrees (indicated by the red arrow). The former region is at the tip clearance region, very little influenced by the unsteadiness, while the latter experienced a strong oscillation at different time steps, with the valley travelling from the left side to the right side then returning to the left side. According to Figure 13, the latter region is near the pressure side of the tip blade, exactly located in the leakage vortex trajectory after the shock, on its way to hit the adjacent pressure side and to develop downstream. The oscillation of pressure valley indicated that the tip leakage vortex was no longer stable at near stall point and was oscillating in the blade passage.

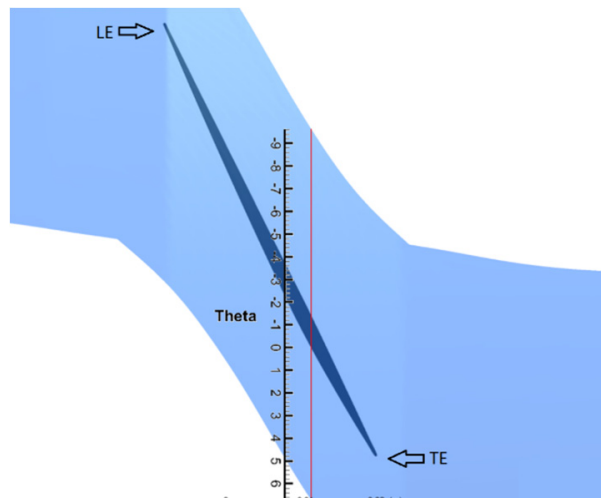

Figure 13 Circumferential Line Location on the Shroud Surface

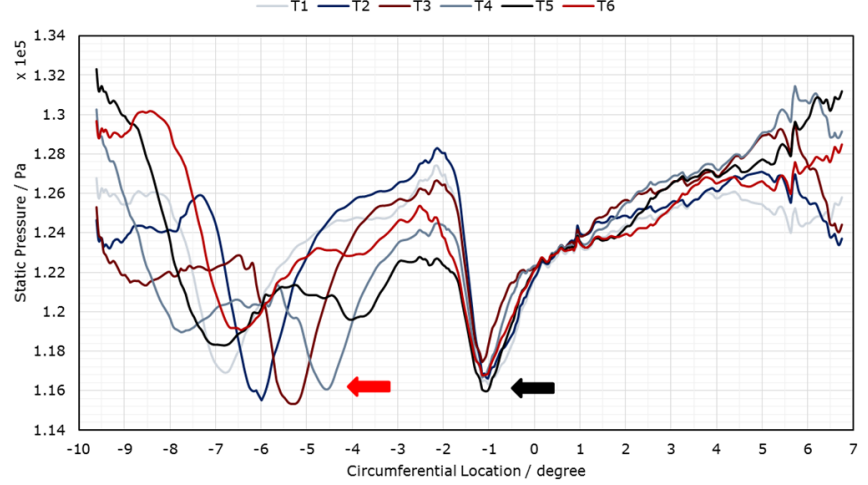

Figure 14 Circumferential Distribution of Casing Pressure at a Certain Axial Location

Figure 15 can clearly illustrate the above phenomena, with black dashed line indicated the same axial location in Figure 13 and Figure 14. Interacted with the shock and the parallel small vortex, tip leakage vortex started to swing tangentially at a distance after the shock. This resulted in a small oscillation, developing downstream with an increasing amplitude. As is known, tip leakage vortex has a lower static pressure value and a lower axial velocity than the mainstream. Every time the trajectory of leakage vortex swept over a certain point, that location would experience a drop in static pressure as well as axial velocity, which is the origin of the oscillation in Figure 14. Eventually, it caused the oscillation of overall parameters such as outlet flow angle, pressure ratio or efficiency.

In general, the unsteadiness of the rotor at near stall point is mainly manifested at the top region, closely related to the tip leakage vortex. The unsteady characteristics in middle span or root span can be totally ignored in comparison. Neither the tip leakage vortex nor the shock alone is the origin of the unsteadiness. It was found that the leakage vortex became unstable after the interaction with the shock and experienced a stronger oscillation when developing downstream. The most unstable region in this transonic rotor is near the pressure side of the tip blade, which is similar to the conclusions (Du et al., 2013) for Darmstadt Rotor 1. 


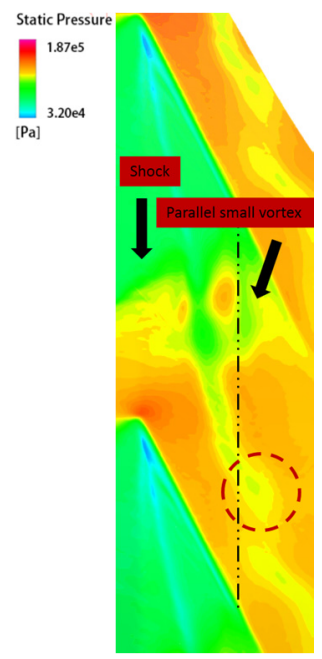

a) $t=1 / 6 T$

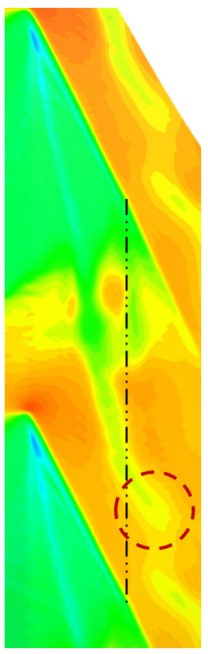

b) $t=2 / 6 T$

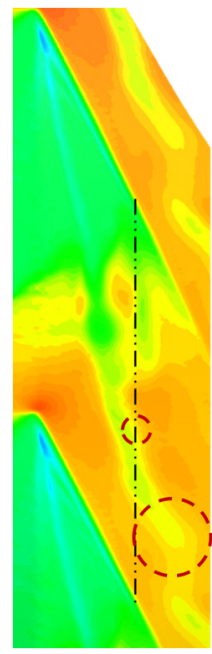

c) $t=3 / 6 T$

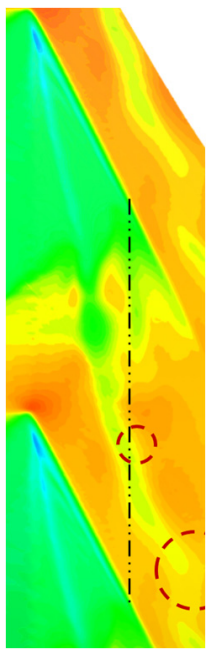

d) $t=4 / 6 T$

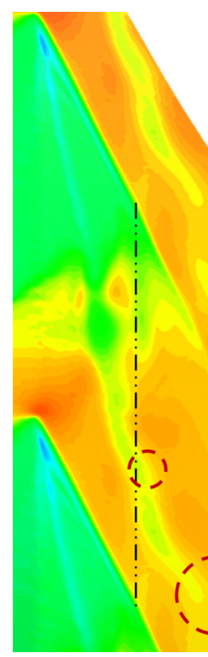

e) $t=5 / 6 T$

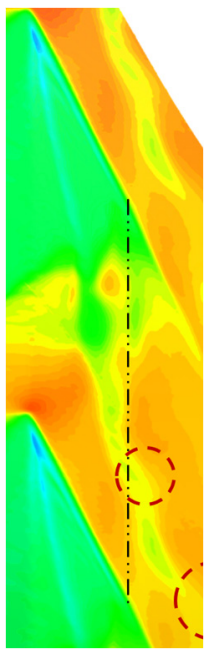

f) $t=6 / 6 T$

Figure 15 Casing Pressure Contour in One Period

\section{Detailed Structure of Tip Leakage Flow}

DES calculation can obtain detailed information of the top flow field than RANS and may provide some clues for the unsteady characteristic mentioned above. The general structure of tip leakage flow can be clearly observed in Figure 16, with shock position indicated by dashed line. The vortex structures are in three different forms as the operating condition changes.

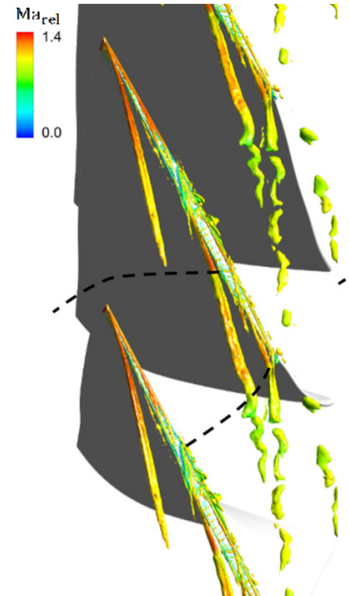

a) Near choke point
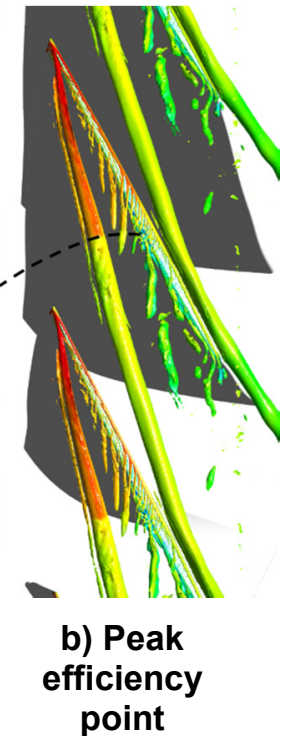

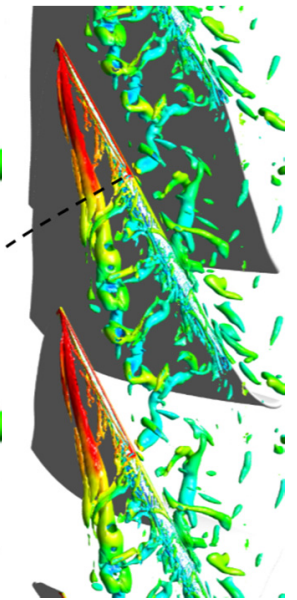

c) Near stall point

\section{Figure 16 Lambda-2 isosurface at top region of $\mathbf{R} 1$ (colored by relative Mach number)}

At the near choke point, there are two shocks, one is the bow shock near the leading edge and the other is the passage shock near the trailing edge. Under this condition, the pressure gradient in the tip clearance is relatively small and the leakage vortex started from the leading edge is weak as well. As a result, the vortex core was more slender in Figure 16 a) and vanished directly after the bow shock. Meanwhile, the leakage vortex was too weak to draw downstream leakage fluid into, which led to another vortex system after the middle chord of the blade. At peak efficiency point, however, the blade load increased and the leading-edge leakage vortex became stronger, so that most leakage fluid can be drawn into the main leakage vortex. The characteristics of the leakage vortex were kept so well in the developing process that the vortex core remained continuous when passing through the shock with a slight expansion in volume, which indicates a stable flow state at peak efficiency point. At near stall point, the entire top flow field had a very rich flow pattern, and there were many small vortex structures after the shock. Some of the small vortexes were developed from the main leakage vortex. The other parts were from the secondary leakage, that is, after imprinting the pressure surface of the adjacent blade, the leakage vortex leaked to the next blade passage again through the tip clearance of the adjacent blade.

The complex flow field at top region is consist with the strong unsteadiness mentioned above at near stall point. The static pressure oscillation in Figure 15 was caused by the "shedding" of small vortexes after the shock. The small vortexes didn't exist at near choke point or peak efficiency point and mainly came from the main leakage vortex, which is probably caused by the interaction with the shock. When passing though the bow shock, the tip leakage vortex at near stall point changed from a single solid core to many separate vortexes.

Figure 17 is the helicity distribution of different crossflow planes at near stall point, which is used to characterize the intertwining degree of the fluid around leakage vortex core, with the blade surface colored by static pressure, the shock position indicated by the black dotted line, and the beginning of the leakage vortex indicated by the black arrow. The vortex core before the shock was concentrated and slowly increasing in volume. After the shock, the helicity distribution was dispersed and not concentrated anymore, which indicated that the fluid no longer moved around the vortex core tightly after the shock. The distance between the four crossflow planes can be approximated as isometric, but the helicity distribution before and after the shock surface is quite different, which 
means that the vortex core experienced an abrupt change in its internal structure. Combined with the vortex structure in Figure $16 \mathrm{c}$ ), we can conclude that a vortex breakdown took place after the interaction between leakage vortex and the shock.

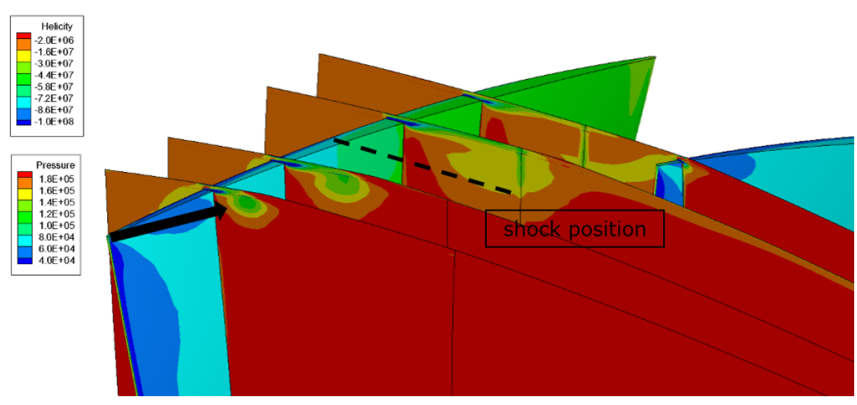

Figure 17 Helicity Distribution on Crossflow Planes at near Stall Point (with blade surface colored by static pressure)

The breakdown process can be clearly illustrated by Figure 18, which is a transient lambda-2 isosurface colored by relative Mach number. It is confirmed that the tip leakage vortex changed to a three-dimensional structure and was not axisymmetric anymore when passing through the shock. The vortex core changed its direction to a perpendicular path and started to rotate around the original one when developing downstream, which is the typical structure of a spiral-type breakdown. The structure after the onset of the breakdown process is not stable, with rotating phase related to the flow time, thus causing strong unsteadiness. This contributes a lot to our understanding of the oscillation after the shock in Figure 15 that, in nature, the unsteady characteristic is not an oscillation, even not a vortex shedding process, but a manifestation of three dimensional phenomena in twodimensional space. The underlying reason behind is the spiral-type vortex breakdown after the interaction with the shock.

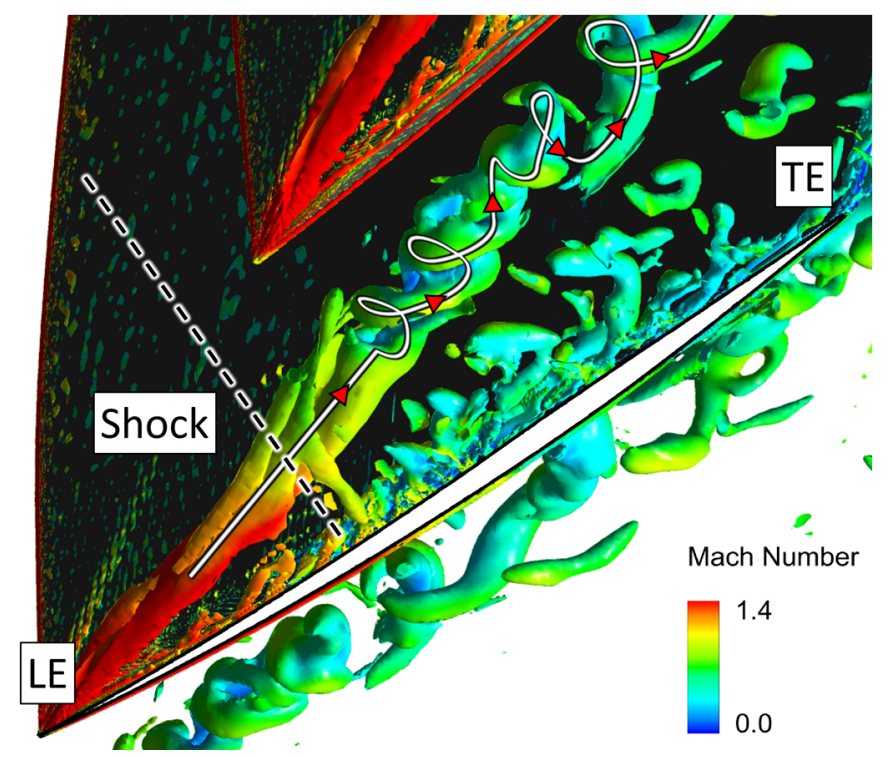

Figure 18 Sketch for Spiral-type Breakdown of Tip Leakage Vortex at Near Stall Point
To the author's knowledge, this is probably the first time that a detailed structure of the breakdown process for the tip leakage vortex in a transonic compressor is obtained in numerical investigations. In addition, PIV (particle image velocimetry) measurements of a transonic compressor near stability limit were conducted (Brandstetter et al., 2018), whose results are in great agreement with the calculation results in present paper, as shown in Figure 19. The small vortices produced by the vortex breakdown are distributed in the top passage, causing a large blockage effect. The low energy fluid may subsequently result in leading-edge spillage, thus inducing a spike-type stall inception. Therefore, how to postpone or eliminate the breakdown of tip leakage vortex is one of the important ways to enhance the stability at near stall point and enlarge the surge margin of transonic compressors.

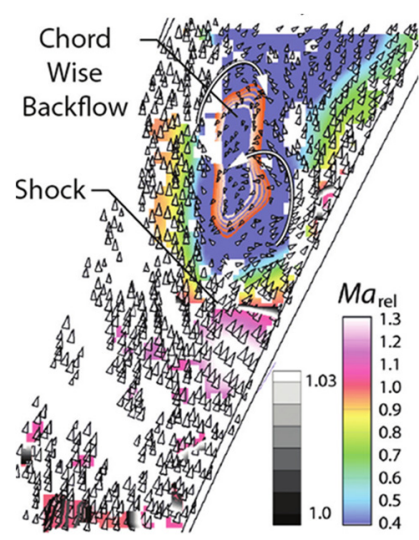

a) PIV results

(Brandstetter et al., 2018)

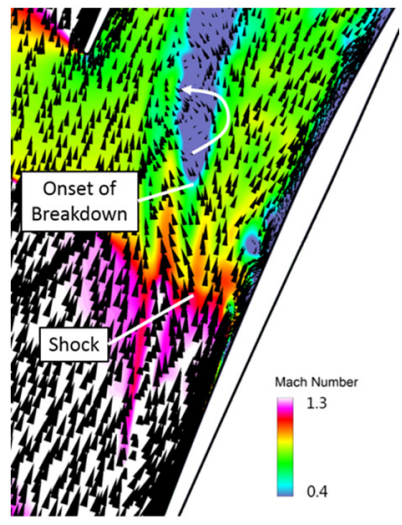

b) DES results in present study

\section{Figure 19 Spiral Vortex Breakdown at Near Stall Point}

\section{CONCLUSIONS}

In this paper, a numerical investigation of a transonic compressor rotor using detached-eddy simulation (DES) method is conducted at three working conditions, focused on the structure of tip leakage flow, the interaction with shock wave and the unsteady characteristics.

Strong unsteadiness was found at near stall point. The affected area is mainly located at top region, causing a considerable fluctuation in overall performances. The most unstable region for this transonic rotor is in the rotor passage near the pressure side of the tip blade, which is the result of the interaction between tip leakage vortex and the shock.

A detailed structure of tip leakage flow was captured, which has a close relationship with the working condition. At the near stall point, a vortex breakdown can be observed downstream the bow shock. While, at near choke point or peak efficiency point, tip leakage vortex breakdown did not take place. The breakdown process at near stall point was confirmed in a spiral-type form. The vortex core changed its direction to a perpendicular path and started to rotate around the original one when developing downstream. The breakdown of tip leakage vortex generated unstable small vortices and was the fundamental cause of the unsteadiness at near stall point. 


\section{NOMENCLATURE}

DES Detached-eddy simulation

$R A N S$ Reynolds-averaged Navier-Stokes

$B P F \quad$ Blade passing frequency

$C_{D E S} \quad$ A coefficient in DES97 model

$U D F \quad$ User-defined function

$\xi_{D E S} \quad$ A criterion to distinguish LES region from RANS region

$\tilde{d} \quad$ DES length scale

$d \quad$ Near-wall distance

$\Delta \quad$ Local grid scale

$\mathrm{Ma}_{\text {rel }} \quad$ Relative Mach number

LES Large eddy simulation

$P S D \quad$ Power spectral density

PSV Particle image velocimetry

\section{References}

Biela, C., Muller, M.W., Schiffer, H.P. and Zscherp, C., 2008, January. Unsteady pressure measurement in a single stage axial transonic compressor near the stability limit. In ASME Turbo Expo 2008: Power for Land, Sea, and Air (pp. 157-165). American Society of Mechanical Engineers. doi: 10.1115/GT2008-50245

Brandstetter, C. and Schiffer, H.P., 2018. PIV measurements of the transient flow structure in the tip region of a transonic compressor near stability limit. Journal of the Global Power and Propulsion Society, 2, 303-316. doi: 10.22261/JGPPS.JYVUQD

Denton, J.D., 1993, May. Loss mechanisms in turbomachines. In ASME 1993 International Gas Turbine and Aeroengine Congress and Exposition (pp. V002T14A001-V002T14A001). American Society of Mechanical Engineers. doi: 10.1115/93-GT-435

Deppe, A., Saathoff, H. \& Stark, U., 2008. Discussion: "Criteria for Spike Initiated Rotating Stall" (Vo, H. D., Tan, C. S., Greitzer, E. M., 2008, ASME J. Turbomach., 130, p. 011023). Journal of Turbomachinery, 130(1). doi: 10.1115/1.2750673

Du, J., Lin, F., Zhang, H. and Chen, J., 2010. Numerical investigation on the self-induced unsteadiness in tip leakage flow for a transonic fan rotor. Journal of turbomachinery, 132(2), p.021017. doi: 10.1115/1.3145103

Du, J., Lin, F., Chen, J., Nie, C. and Biela, C., 2013. Flow structures in the tip region for a transonic compressor rotor. Journal of Turbomachinery, 135(3), p.031012. doi: 10.1115/1.4006779

Furukawa, M., Inoue, M., Saiki, K. and Yamada, K., 1998, June. The role of tip leakage vortex breakdown in compressor rotor aerodynamics. In ASME 1998 International Gas Turbine and Aeroengine Congress and Exhibition (pp. V001T01A054-V001T01A054). American Society of Mechanical Engineers. doi: 10.1115/98-GT-239

Hoffman, W.H. and Ballman, J., 2003. Some aspects of tip vortex behavior in a transonic turbocompressor. ISABE paper, 1223, p.2003.

Hoying, D.A., Tan, C.S., Vo, H.D. and Greitzer, E.M., 1998, June. Role of blade passage flow structures in axial compressor rotating stall inception. In ASME 1998 International Gas Turbine and Aeroengine Congress and Exhibition (pp. V001T01A138-V001T01A138). American Society of Mechanical Engineers. doi: 10.1115/98-GT-588

Iim, H., Chen, X.Y. and Zha, G., 2012. Detached-eddy simulation of rotating stall inception for a full-annulus transonic rotor. Journal of Propulsion and Power, 28(4), pp.782-798. doi: 10.2514/1.B34395

Lin, D., Su, X. and Yuan, X., 2018. DDES Analysis of the Wake Vortex Related Unsteadiness and Losses in the Environment of a High-Pressure Turbine Stage. Journal of Turbomachinery, 140(4), p.041001. doi: 10.1115/1.4038736

Puterbaugh, S.L. and Brendel, M., 1997. Tip clearance flow-shock interaction in a transonic compressor rotor. Journal of propulsion and power, 13(1), pp.24-30. doi: 10.2514/2.5146

Riéra, W., Castillon, L., Marty, J. and Leboeuf, F., 2014. Inlet condition effects on the tip clearance flow with zonal detached eddy simulation. Journal of Turbomachinery, 136(4), p.041018. doi: 10.1115/1.4025216

Spalart, P. and Allmaras, S., 1992, January. A oneequation turbulence model for aerodynamic flows. In 30th aerospace sciences meeting and exhibit (p. 439). doi: 10.2514/6.1992-439

Spalart, P.R. et al., 1997. Comments on the Feasibility of LES for Wings, and on a Hybrid RANS/LES Approach. In Advances in DNS/LES. Columbus, OH: Greyden Press, pp. 137-47.

Vo, H.D., 2001. Role of tip clearance flow on axial compressor stability (Doctoral dissertation, Massachusetts Institute of Technology).

Vo, H.D., Tan, C.S. and Greitzer, E.M., 2008. Criteria for spike initiated rotating stall. Journal of turbomachinery, 130(1), p.011023. doi: 10.1115/1.2750674

Yamada, K., Furukawa, M., Nakano, T., Inoue, M. and Funazaki, K., 2004, January. Unsteady three-dimensional flow phenomena due to breakdown of tip leakage vortex in a transonic axial compressor rotor. In ASME Turbo Expo 2004: Power for Land, Sea, and Air (pp. 515-526). American Society of Mechanical Engineers. doi: 10.1115/GT200453745

Yamada, K., Kikuta, H., Iwakiri, K.I., Furukawa, M. and Gunjishima, S., 2013. An explanation for flow features of spike-type stall inception in an axial compressor rotor. Journal of turbomachinery, 135(2), p.021023. doi: 10.1115/1.4007570

Yamada, K., Furukawa, M., Tamura, Y., Saito, S., Matsuoka, A. and Nakayama, K., 2017. Large-Scale Detached-Eddy Simulation Analysis of Stall Inception Process in a Multistage Axial Flow Compressor. Journal of Turbomachinery, 139(7), p.071002. doi: 10.1115/1.4035519

Yan-feng, Z., Wu-li, C. \& Xin-gen, L., 2008. Numerical simulation of the flow characteristic of tip leakage flow in a transonic axial-flow compressor at near stall condition. Journal of Aerospace Power, 23(7), 1293 - 1298. 